\title{
CHARACTERIZATION AND APPORTIONMENT OF SOURCES OF INDOOR AIR PARTICULATE MATTER OF AECD CAMPUS, DHAKA
}

\author{
BILKIS A. BEGUM AND SWAPAN K. BISWAS* \\ Chemistry Division, Atomic Energy Centre, P.O. Box-164, Dhaka, \\ Bangladesh
}

\begin{abstract}
Ambient particulate matter $\left(\mathrm{PM}_{10}\right.$ and $\left.\mathrm{PM}_{2.5}\right)$ samples were collected in different laboratories and sitting rooms at the Atomic Energy Centre Dhaka campus in Dhaka on weekdays using AirMetrics Samplers from September to December 2006. The samples were analyzed for elemental concentrations by ED XRF method. Black carbon was analyzed by reflectance. The data sets were analyzed by reconstructive mass (RCM) methods to check the mass closer and also to identify the possible sources of atmospheric aerosols in these closed areas. It was observed that in these closed areas, 74 to $98 \%$ of the particulate mass belong to fine particles mass $\left(\mathrm{PM}_{2.5}\right)$. Mostly three and four sources have been identified in both $\mathrm{PM}_{10}$ and $\mathrm{PM}_{2.5}$ fractions respectively. The sources are soil, combustion products (signature elements are $\mathrm{BC}$ and $\mathrm{OC}$ ), $\mathrm{Pb}$ and $\mathrm{Zn}$ containing sources. It was found that about 70 to $98 \%$ of total mass is black carbon together with organic carbon.
\end{abstract}

Keywords: RCM, PM, AECD campus, XRF method

\section{INTRODUCTION}

Indoor air pollutant concentrations are important in the determination of total human exposure mainly because individuals spend a major fraction of their time indoors ${ }^{(1)}$. Acute respiratory infections (ARI) linked to air pollution are the leading cause of the global burden of disease and account for more than $6 \%$ of the global burden of disease ${ }^{(2,3)}$. Between 1997 and 1999, acute lower respiratory infections (ALRI) were the leading cause of mortality from infectious diseases, with an estimated 3.5-4.0 million annual deaths worldwide, mostly in developing countries ${ }^{(2,3)}$. Exposure to indoor air pollution, especially to particulate matter, has been indicated as a causal agent of respiratory diseases in developing countries ${ }^{(4-7)}$.

Cooking fire, tobacco smoke, and biomass combustion are major sources of air pollution in many developing countries. Fuel burning produces large amount of smoke and other pollutants that are retained within poorly ventilated homes in rural areas. On the other hand, in urban areas, exposure to indoor air pollution has increased due to variety of reasons, including the construction of more tightly sealed buildings, the use of synthetic materials for building and furnishings, and the use of chemical products and households care products. Indoor fumes from cooking in big cities like Dhaka are expected to be less as commercial fuels; especially natural gas and liquid petroleum gas (LPG) mostly used rather than biomass fuel .

Now a days, in the mega cities of developing countries, the number of modern commercial and office buildings are increasing rapidly which have less or no natural ventilation. Fine PM may be trapped in those modern sealed building with central air condition in a system, which might elevate the $\mathrm{PM}_{2.5}$ levels inside the building and cause serious health concern. Moreover, in the conventional room cleaning procedures, fine dust particles usually cannot be removed and consequently may also lead to elevated indoor PM concentrations. Characterization of PM can help for identifying the sources of

${ }^{*}$ Corresponding author 
these fine particles and preventive care may be undertaken to controlling indoor air quality.

Atomic Energy Centre, Dhaka (AECD) was built in 1964 as research laboratory fo promote nuclear technology in the country. The AECD buildings are customized for housing specialized laboratories, basically sealed from external influence. As old buildings, it is expected that fine particles have accumulated over the years and the particulate load are expected to be higher. The main objective of the present study is to assess the indoor air quality in terms of particulate matter (PM) at different rooms of the AECD buildings. PM samples were characterized for black carbon and elemental contents. The concentration data was used to identify and apportion possible sources contributing the indoor air pollutants.

\section{MATERIAL AND METHODS}

\subsection{Sampling with AirMetrics MiniVol Sampler}

The IAP sampling were done in the laboratories of Atomic Energy Centre, Dhaka including a cubical room where the scientists work using AirMetrics MiniVol sampler ${ }^{(8)}$ for collecting both $\mathrm{PM}_{10}$ and $\mathrm{PM}_{2.5}$ samples. The description of sampling location is described in Table 1. Each laboratory and cubical room was monitored once for $24 \mathrm{~h}$ during the sampling period. The AirMetrics MiniVol sampler developed jointly by the U.S. Environmental Protection Agency (EPA) and the Lane Regional Air Pollution Authority was used for both $\mathrm{PM}_{10}$ and $\mathrm{PM}_{2.5}$ sampling and can be used for $\mathrm{PM}$ and gas sampling.

For sampling with MiniVol sampler, the actual flow rate must be 5 liter per minute (lpm) at ambient conditions for proper size fractionation. To ensure a constant flow rate of 5lpm through the size separator at different air temperatures and atmospheric pressures, the sampler flow rate was adjusted for ambient condition of the sampling site. The samplers were set up in the conventional manner with filters. The sampler was placed at the nozzle height of a person.

Both $\mathrm{PM}_{10}$ and $\mathrm{PM}_{2.5}$ samples were collected on Teflon ( $2.0 \mu \mathrm{m}$ pore size) filters. The filters were equilibrated at about $50 \%$ relative humidity and weighted on a microbalance prior to insertion into the filter holder. The sampling was done for $24 \mathrm{hrs}$ in all the places. After sampling, the filter samples were retrieved and returned to the laboratory for weighing and analysis.

\subsection{Pm Mass Determination}

PM masses were measured in the Chemistry Division of the Atomic Energy Centre, Dhaka (AECD) laboratory. The aerosol samples having both $\mathrm{PM}_{10}$ as well as $\mathrm{PM}_{2.5}$ were determined by weighing ${ }^{(9)}$ the filters before and after exposure using a micro balance (METTLER Model MT5) maintaining room temperature approximately at $22{ }^{\circ} \mathrm{C}$ and relative humidity at $50 \%$. The air filters were equilibrated at constant humidity and temperature of the balance room before every weighing. A Po-210 (alpha emitter) electrostatic charge eliminator (STATICMASTER) was used to eliminate the static charge accumulated on the filters before each weighing. The difference in weights for each filter was calculated and the mass of each $\mathrm{PM}_{2.5}$ or $\mathrm{PM}_{10}$ sample was then determined. 
Table. 1.

Description of sampling location with Identification

\begin{tabular}{|c|c|c|}
\hline Sampling location & Sample ID & Activities \\
\hline Trace analytical Laboratory & TAL & Analysis of samples, Pb bricks \\
\hline Chromatography Laboratory & CGL & Analysis of samples \\
\hline Chemistry main Laboratory & CML & $\begin{array}{c}\text { Analysis of samples, burning of biological } \\
\text { samples }\end{array}$ \\
\hline Health physics Laboratory & HPL & Measurement of radioactivity, Pb bricks \\
\hline Class Room & CR & Analysis of samples \\
\hline Magnetic Material Division & MMD & Pb bricks \\
\hline $\begin{array}{c}\text { Non-Destructive Testing } \\
\text { Laboratory }\end{array}$ & NDT & Conference/Meeting \\
\hline Auditorium Room & AUR & Analysis of samples \\
\hline Electronics Laboratory & EL & Repair and maintenances of equipments \\
\hline $\begin{array}{c}\text { Magnetic Material Division, } \\
\text { XRD }\end{array}$ & MMDX & Repair and maintenances of equipments \\
\hline Electric Section & ER & Reading place \\
\hline Library Room & EW & Repair and maintenances of equipments \\
\hline Electrical Workshop & GAD & Preparation of glass apparatus \\
\hline Glass Blowing Section & EPD1 & Study of nuclear reaction \\
\hline $\begin{array}{c}\text { Experimental Physics Division } \\
\text { Lab1 }\end{array}$ & EPD2 & Study of nuclear reaction \\
\hline Accelerator Facilities Laboratory & AFD & Ansis of samples, Pb bricks \\
\hline
\end{tabular}

*These spaces are open to atmosphere and are qualitatively different from other spaces.

The concentration of black carbon (BC) in the fine fraction of the samples was determined by reflectance measurement using an EEL type Smoke Stain Reflectometer ${ }^{(10)}$. The concentrations of $\mathrm{BC}$ are operationally defined based on the amount of reflected light that is absorbed by the filter sample and an assumed mass absorption coefficient. It is related to the concentration of light absorbing carbon through standards of carbon with known areal density. Secondary standards of known black carbon concentrations are used to calibrate the Reflectometer.

$\mathrm{BC}$ could be measured by reflectance method for the $\mathrm{PM}_{10}$ and $\mathrm{PM}_{2.5}$ mass. The $\mathrm{OC}$ was calculated from suitable $\mathrm{EC}(\mathrm{BC}) / \mathrm{TC}$ ratios obtained from literature. Emissions from diesel engines as well as from oil and coal fired stationary sources exhibit $\mathrm{EC}(\mathrm{BC}) / \mathrm{TC}$ ratios $^{(11,12)}$ in the range of $0.6-0.7$. In contrast, for emissions from biomass combustion $\mathrm{EC}(\mathrm{BC}) / \mathrm{TC}$ ratios is around 0.3 that have been reported in some other studies ${ }^{(13,14)}$.

\subsection{Elemental Analysis}

A radioisotope-induced energy dispersive X-ray fluorescence (EDXRF) ${ }^{(15,16)}$ spectrometer was used to analyze the elemental composition of all of the filter samples. Energy-Dispersive X-ray Fluorescence (EDXRF) analysis employs detectors that directly measure the energy as well as the intensity of the $\mathrm{X}$-rays by collecting ionization produced in a suitable detecting medium. The EDXRF analysis based on Cd-109 radioisotope (emitting Ag-K x-rays) excitation has been used ${ }^{(17)}$ for the present study. The EDXRF spectra were processed and quantified using the Qualitative X-ray Analysis System (QXAS) and the Analysis of X-ray spectra by Iterative Least-square fitting (AXIL) ${ }^{(16)}$. 
All samples were analyzed using a live time of 3000s. The concentration calibration was carried out by determining the sensitivity factor for each of the elements using MicroMatter thin standards in order to compensate for any matrix effect in the analysis. The sensitivity factor is expressed as the rate of change of analyte-line intensity with a change in the analyte concentration. The sensitivity ${ }^{(18)}$ of each element was calculated based on its average peak areas of five independent measurement of each standard. The calibration curve was constructed by plotting the sensitivities of the standard elements as a function of their atomic numbers (Figure 1). The calculations of elemental concentrations in the samples were done by using resnective calihration factors.

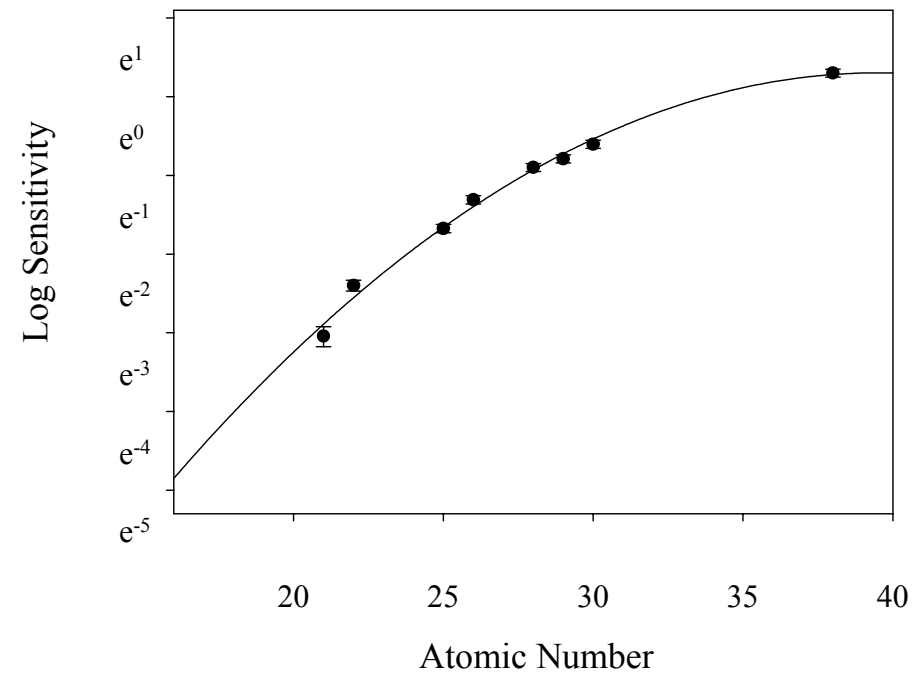

Fig. 1. X-ray yield curve for concentration calibration constructed from MicroMatter thin standards

The EDXRF spectra were processed and quantified using the Qualitative X-ray Analysis System (QXAS) and the Analysis of X-ray spectra by Iterative Least-square fitting $\left(\right.$ AXIL) ${ }^{(16)}$. All samples were analyzed using a live time of $3000 \mathrm{~s}$. Calibration of the EDXRF spectrometer was performed using MicroMatter thin standards (MicroMatter Co., Eastsounds, WA, USA) of suitable concentrations.

The minimum detection limit (MDL) of the method has been studied with MicroMatter thin standards. From the consideration of statistical uncertainty associated with X-ray counting, the MDL is defined as the amount of an element in ppm present in the sample, which will yield $\mathrm{x}$-ray intensity equal to 3 times of the background under the photo-peak. Table 6 presents the limits of detection (LoD) as spectrometer limits expressed in $\mu \mathrm{g} / \mathrm{m}^{3}$, for AirMetric sample, the flow rate used $5 \mathrm{l} / \mathrm{min}$. XRF was used to analyze $\mathrm{K}, \mathrm{Ca}, \mathrm{Ti}, \mathrm{Cr}$, $\mathrm{Mn}, \mathrm{Fe}, \mathrm{Cu}$ and $\mathrm{Zn}$. 
Table. 6.

The MDL values in $\mu \mathrm{g} / \mathrm{m}^{3}$

\begin{tabular}{|l|l|}
\hline Element & MDL \\
\hline $\mathrm{K}$ & 2.55 \\
\hline $\mathrm{Ca}$ & 1.60 \\
\hline $\mathrm{Sc}$ & 1.24 \\
\hline $\mathrm{Ti}$ & 0.72 \\
\hline $\mathrm{V}$ & 0.62 \\
\hline $\mathrm{Cr}$ & 0.38 \\
\hline $\mathrm{Mn}$ & 0.46 \\
\hline $\mathrm{Fe}$ & 0.21 \\
\hline $\mathrm{Ni}$ & 0.10 \\
\hline $\mathrm{Cu}$ & 0.12 \\
\hline $\mathrm{Zn}$ & 0.15 \\
\hline $\mathrm{Pb}$ & 0.43 \\
\hline
\end{tabular}

XRF was used to analyze 8 elements, $\mathrm{K}, \mathrm{Ca}, \mathrm{Cr}, \mathrm{Mn}, \mathrm{Fe}, \mathrm{Cu}, \mathrm{Zn}$ and $\mathrm{Pb}$. Quality control of the XRF elemental analysis is done by analyzing certified reference materials and by comparing the results from the various techniques ${ }^{(19)}$ of the same aerosol filters. $\mathrm{Al}, \mathrm{Si}$ and Ti were calculated from the Mason data ${ }^{(20)}$.

\subsection{DATA ANALYSIS}

\section{Reconstructed mass (RCM) method}

The analysis of PM samples provides elemental concentrations that permit the development of fingerprints for a variety of particle sources ${ }^{(21)}$. It is useful to combine some of these elements and estimate the concentrations of compounds likely to represent most of the measured element such as estimating the amount of ammonium sulfate from the measured sulfur concentration. It is also possible to derive other combinations of pure elements that represent signatures for interesting aerosol components. These elements are called pseudo-elements such as "soil". Thus these composite variables and pseudoelements help to have a better understanding of possible sources and their contributions to the average ambient aerosol ${ }^{(22)}$.

Smoke: Fine potassium is an accepted indicator for smoke from biomass burning/brick kiln. Most biomass fuels are characterized by high-alkali contents ${ }^{(23)}$ leading to high concentrations of fine aerosols in the flue gases ${ }^{(24)}$. In order to obtains a reliable smoke indicator from the fine potassium, it is necessary to subtract the fine potassium associated with soil and sea salt component from total $\mathrm{K}^{(25)}$. As the samples were analyzed by XRF method, it is not possible to measure $\mathrm{Na}$ and $\mathrm{Cl}$. Hence, smoke is obtained by using the following equation, 
Smoke $=($ Ktot $-0.6 * \mathrm{Fe})$

Soil : Wind blown soil is composed mainly of the oxides of $\mathrm{Mg}, \mathrm{Al}, \mathrm{Si}, \mathrm{Ca}, \mathrm{Ti}$ and $\mathrm{Fe}$ with other many trace elements. The average composition of sandstone and sedimentary rocks and the summation of the 5 major oxides of $\mathrm{Al}, \mathrm{Si}, \mathrm{Ca}, \mathrm{Ti}$ and $\mathrm{Fe}$ account for more that $85 \%$ of the total composition. In this study, the $\mathrm{Si} / \mathrm{Fe}$ and $\mathrm{Al} / \mathrm{Si}$ ratio from mason data $^{(20)}$ in order to calculate $\mathrm{Al}$ and $\mathrm{Si}$ concentrations. So the equation for soil is

Soil $=2.20 * A l+2.49 * S i+1.63 * C a+1.94 * T i+2.42 * F e$

This equation assumes that the two common oxides of iron $\mathrm{Fe}_{2} \mathrm{O}_{3}$ and $\mathrm{FeO}$ occur in equal proportions. The factor of 2.42 for iron also includes the estimate for $\mathrm{K}_{2} \mathrm{O}$ in soil through the $(\mathrm{K} / \mathrm{Fe})=0.6$ ratio for sedimentary soils. The sum of the composite variables was expected to provide a reasonable estimate of $\mathrm{PM}_{10}$ and $\mathrm{PM}_{2.5}$ mass for comparison with the measured gravimetric mass collected on the filters. So, the definition of the reconstructed mass is,

$$
R C M=\left(\mathrm{NH}_{4}\right)_{2} \mathrm{SO}_{4}+\text { Salt }+ \text { Soil }+ \text { Smoke }+\mathrm{Zn}+\mathrm{Pb}+\mathrm{BC}+\mathrm{OC}
$$

$\left(\mathrm{NH}_{4}\right)_{2} \mathrm{SO}_{4}$ and Salt are the terms for sulphate and sea salt. During calculation these terms have been omitted, as they were not calculated in this study.

\section{RESULT AND DISCUSSIONS}

The quality of indoor air depends on the ventilations. It has found that most traditionally used biofuel stoves have a thermal efficiency between $10-30 \%{ }^{(26,27)}$ and emit large amount of pollutants, exposing users to high concentrations of toxic and carcinogenic emissions ${ }^{(28)}$. In general, the PM emission rate increased with increasing temperature ${ }^{(29)}$ and found that elemental carbon formation increases with increase of combustion temperature ${ }^{(30)}$. It has been found that fuel used in the closed environment (less ventilation) increase the PM level in indoor environment ${ }^{(31)}$.

\subsection{Comparison of $\mathrm{PM}_{10}$ and $\mathrm{PM}_{2.5}$}

All the samples were collected on working week days. In the indoor air (IA) data set, a total of 17 samples in each of the $\mathrm{PM}_{10}$ and $\mathrm{PM}_{2.5}$ mass are available for analysis. Table 2 shows the measured mass (both $\mathrm{PM}_{10}$ and $\mathrm{PM}_{2.5}$ ) and black carbon concentrations. It was found that the $\mathrm{PM}_{10}$ and $\mathrm{PM}_{2.5}$ masses are lower than the Bangladesh national ambient air quality standard, which is set as 150 and $65 \mu \mathrm{g} / \mathrm{m}^{3}$ (24 $\mathrm{h}$ average) respectively, in most of the sampling locations except in few laboratories where the values of $\mathrm{PM}_{2.5}$ is much higher than the standard. 
Table. 2.

The PM and BC concentrations $\left(\mu \mathrm{g} / \mathrm{m}^{3}\right)$.

\begin{tabular}{|c|c|c|c|c|c|}
\hline $\begin{array}{l}\text { Sample } \\
\text { ID }\end{array}$ & Fraction & $\begin{array}{l}\text { Concentration } \\
\mu \mathrm{g} / \mathrm{m}^{3}\end{array}$ & $\begin{array}{l}\text { Black } \\
\text { carbon } \\
\mu \mathrm{g} / \mathrm{m}^{3}\end{array}$ & BC/Mass & PM2.5/PM10 \\
\hline \multirow{2}{*}{ TAl } & $\mathrm{PM}_{2.5}$ & 28.8 & 22.0 & 76.5 & \multirow[b]{2}{*}{0.80} \\
\hline & $\mathrm{PM}_{10}$ & 35.8 & 23.9 & 66.6 & \\
\hline \multirow{2}{*}{ CGL } & $\mathrm{PM}_{2.5}$ & 29.3 & 22.7 & 77.5 & \multirow[b]{2}{*}{0.94} \\
\hline & $\mathrm{PM}_{10}$ & 31.1 & 23.8 & 76.7 & \\
\hline \multirow{2}{*}{ CML } & $\mathrm{PM}_{2.5}$ & 138 & 30.4 & 22.1 & \multirow[b]{2}{*}{0.91} \\
\hline & $\mathrm{PM}_{10}$ & 151 & 30.8 & 20.3 & \\
\hline \multirow{2}{*}{ HPL } & $\mathrm{PM}_{2.5}$ & 56.4 & 42.3 & 75.1 & \multirow[b]{2}{*}{0.94} \\
\hline & $\mathrm{PM}_{10}$ & 60.2 & 39.3 & 65.4 & \\
\hline \multirow{2}{*}{ CRP } & $\mathrm{PM}_{2.5}$ & 25.8 & 17.4 & 67.3 & \multirow[b]{2}{*}{0.98} \\
\hline & $\mathrm{PM}_{10}$ & 26.5 & 16.8 & 63.7 & \\
\hline \multirow{2}{*}{ MMD } & $\mathrm{PM}_{2.5}$ & 57.2 & 26.8 & 46.9 & \multirow[b]{2}{*}{0.84} \\
\hline & $\mathrm{PM}_{10}$ & 68.0 & 29.1 & 42.8 & \\
\hline \multirow{2}{*}{ NDT } & $\mathrm{PM}_{2.5}$ & 31.4 & 26.8 & 85.4 & \multirow[b]{2}{*}{0.86} \\
\hline & $\mathrm{PM}_{10}$ & 36.5 & 32.2 & 88.3 & \\
\hline \multirow{2}{*}{ AU } & $\mathrm{PM}_{2.5}$ & 36.0 & 28.6 & 79.2 & \multirow[b]{2}{*}{0.92} \\
\hline & $\mathrm{PM}_{10}$ & 39.1 & 24.5 & 62.5 & \\
\hline \multirow{2}{*}{ EL } & $\mathrm{PM}_{2.5}$ & 32.1 & 25.8 & 80.4 & \multirow[b]{2}{*}{0.80} \\
\hline & $\mathrm{PM}_{10}$ & 40.0 & 23.8 & 59.5 & \\
\hline \multirow{2}{*}{ GAD } & $\mathrm{PM}_{2.5}$ & 114 & 52.2 & 46.0 & \multirow[b]{2}{*}{0.87} \\
\hline & $\mathrm{PM}_{10}$ & 131 & 53.0 & 40.5 & \\
\hline \multirow{2}{*}{ EW } & $\mathrm{PM}_{2.5}$ & 116 & 47.0 & 40.6 & \multirow[b]{2}{*}{0.78} \\
\hline & $\mathrm{PM}_{10}$ & 149 & 51.9 & 34.9 & \\
\hline \multirow{2}{*}{ ES } & $\mathrm{PM}_{2.5}$ & 113 & 46.4 & 41.1 & \multirow[b]{2}{*}{0.74} \\
\hline & $\mathrm{PM}_{10}$ & 153 & 50.2 & 32.9 & \\
\hline \multirow{2}{*}{ AFD } & $\mathrm{PM}_{25}$ & 137 & 59.6 & 43.4 & \multirow[b]{2}{*}{0.91} \\
\hline & $\mathrm{PM}_{10}$ & 150 & 58.3 & 38.7 & \\
\hline \multirow{2}{*}{ LR } & $\mathrm{PM}_{2.5}$ & 45.4 & 37.9 & 83.4 & \multirow[b]{2}{*}{0.85} \\
\hline & $\mathrm{PM}_{10}$ & 53.1 & 31.7 & 59.8 & \\
\hline \multirow{2}{*}{ SED1 } & $\mathrm{PM}_{2.5}$ & 35.9 & 16.7 & 46.6 & \\
\hline & $\mathrm{PM}_{10}$ & 43.2 & 16.5 & 38.3 & 0.83 \\
\hline SED? & $\mathrm{PM}_{2.5}$ & 50.7 & 26.7 & 52.6 & \\
\hline SEDL & $\mathrm{PM}_{10}$ & 50.8 & 27.2 & 53.6 & 1.00 \\
\hline & $\mathrm{PM}_{2.5}$ & 25.7 & 17.3 & 67.2 & \\
\hline MIVIDX & $\mathrm{PM}_{10}$ & 27.4 & 15.8 & 57.7 & 0.94 \\
\hline
\end{tabular}

It was found that in $\mathrm{PM}_{10}$ fraction about 74 to $99 \%$ is $\mathrm{PM}_{2.5}$ mass. This is because inside the campus, the rooms were cleaned by conventional method. As a result, the fine PM are always accumulated and trapped, as there are no ways to escape the dust particles. The higher PM mass concentrations were found in Chemistry Main Lab, Electrical Section, Electrical workshop, Glass Apparatus Fabrication Lab and Accelerator Facility Division. The main reason of this high value is due to public function as these divisions give the analytical services to public. In these divisions (CML and AFD), many analytical activities are done that are related to analytical service to other organizations and patients and do research jointly with the Universities as well as. In CML, for analytical research, many samples like biological and environmental samples were prepared for analysis by a combustion procedure. On the other hand in ES, EW, and GAD, mostly the repair and maintenance of electrical equipment and glassware have to be done on demand. The other reason of high PM mass is organic carbon that mainly comes from the kitchen located to the southeastern side of the sampling location. 


\subsection{Enrichment Factors}

In order to investigate the variation on the concentration profiles of different trace metals, the enrichment factors (EF) compared to the crustal abundances have been calculated. The crustal abundance data were taken from Mason ${ }^{(20)}$. Fe was chosen as the reference element as it was not possible to determine $\mathrm{Al}$ or Ti concentrations in the samples by the XRF method. The enrichment factors (EF) are given by

$$
E F_{i}=\frac{C_{i}}{C_{F e}} / \frac{A_{i}}{A_{F e}}
$$

where,

$E F_{i}=$ Enrichment factor for the element, i

$C_{i}=$ Observed concentration of the element, $\mathrm{i}$, and

$A_{i}=$ Crustal abundance of the element, i

The subscript "Fe" refers to the relevant quantities for Fe

The average EF values calculated for the samples collected from different sites are presented in Table 3. As a "rule of thumb", the enrichment factors greater than $\sim 10$ indicate element additions over reference levels that may be attributed to anthropogenic influences ${ }^{(32)}$. In general the trace metals determined are not highly enriched suggesting the bricks are manufactured during pre-anthropogenic period.

Most of the elements like $\mathrm{Cu}, \mathrm{Zn}$, and $\mathrm{Pb}$ considered to be of anthropogenic origin have EF values more than 10. It may be concluded that these elements come from anthropogenic activities $\mathrm{Pb}, \mathrm{Cu}$ and $\mathrm{Zn}$ may come from soldering of electrical equipment or $\mathrm{Pb}$ from $\mathrm{Pb}$ brick, which is used as a radiation protection.

Table. 3.

Enrichment factors of the $\mathbf{P} \mathbf{M}_{2.5}$ samples collected from different laboratories at AECD campus

\begin{tabular}{|c|c|c|c|c|c|c|c|c|c|c|}
\hline \multirow{2}{*}{ Location } & \multicolumn{9}{|c|}{$\mathrm{PM}_{2.5}$} & \multicolumn{5}{c|}{$\mathrm{PM}_{10}$} \\
\cline { 2 - 13 } & $\mathrm{Ca}$ & $\mathrm{Fe}$ & $\mathrm{Cu}$ & $\mathrm{Zn}$ & $\mathrm{Pb}$ & $\mathrm{Ca}$ & $\mathrm{Fe}$ & $\mathrm{Cu}$ & $\mathrm{Zn}$ & $\mathrm{Pb}$ \\
\hline TAL & 0 & 1 & 142 & 159 & 0 & 0 & 1 & 190 & 205 & 808 \\
\hline CGL & 0 & 1 & 180 & 333 & 0 & 0 & 1 & 189 & 361 & 0 \\
\hline CML & 0 & 1 & 108 & 93 & 1216 & 0 & 1 & 160 & 162 & 1258 \\
\hline HPL & 0 & 1 & 201 & 39 & 0 & 0 & 1 & 155 & 38 & 0 \\
\hline CR & 0 & 1 & 169 & 34 & 0 & 0 & 1 & 194 & 43 & 0 \\
\hline MMD & 0 & 1 & 201 & 214 & 811 & 0 & 1 & 144 & 222 & 0 \\
\hline NDT & 0 & 1 & 106 & 76 & 720 & 0 & 1 & 140 & 70 & 739 \\
\hline AUR & 0 & 1 & 200 & 61 & 1268 & 0 & 1 & 134 & 257 & 837 \\
\hline EL & 0 & 1 & 145 & 184 & 966 & 0 & 1 & 122 & 183 & 963 \\
\hline MMDX & 0 & 1 & 200 & 121 & 0 & 0 & 1 & 198 & 102 & 0 \\
\hline ES & 0 & 1 & 208 & 84 & 0 & 0 & 1 & 71 & 53 & 0 \\
\hline LR & 0 & 1 & 197 & 118 & 0 & 0 & 1 & 388 & 61 & 0 \\
\hline EW & 0 & 1 & 1944 & 54 & 0 & 0 & 1 & 610 & 68 & 2168 \\
\hline GAD & 0 & 1 & 376 & 79 & 0 & 0 & 1 & 470 & 83 & 0 \\
\hline SED1 & 0 & 1 & 976 & 66 & 1867 & 0 & 1 & 934 & 43 & 0 \\
\hline SED2 & 0 & 1 & 1368 & 64 & 0 & 0 & 1 & 1655 & 80 & 0 \\
\hline AFD & 0 & 1 & 380 & 79 & 2483 & 0 & 1 & 520 & 98 & 0 \\
\hline
\end{tabular}


Tables 4 and 5 present the black carbon (BC), organic carbon (OC) and possible sources of PM (both $\mathrm{PM}_{10}$ and $\mathrm{PM}_{2.5}$ particulates) apportioned by RCM method. The soil, smoke, fugitive $\mathrm{Pb}, \mathrm{Zn}$ source, $\mathrm{BC}$ and $\mathrm{OC}$ could be estimated from the $\mathrm{PM}_{2.5}$ and $\mathrm{PM}_{10}$. The high PM mass in Chemistry Main Lab, Electrical Section, Electrical workshop, Glass Apparatus Fabrication Lab and Accelerator Facility Division is due to high OC. Smoke is low as these labs did not use biomass burning for cooking or other purpose. But in CML, they burn fish flash/biological materials for their experiment, therefore OC is high. On the other hand, in Electrical Section, Electrical workshop, Glass Apparatus Fabrication Lab and Accelerator Facility Division, the OC values are also high that comes from kitchen.

Table. 4.

Source apportionment from $\mathrm{PM}_{10}$ samples $\left(\mu \mathrm{g} / \mathrm{m}^{3}\right)$ (IAP) collected from AECD campus

\begin{tabular}{|c|c|c|c|c|c|c|c|c|c|}
\hline $\begin{array}{c}\text { PM }_{10} \\
\text { Sample }\end{array}$ & BC & Soil & Smoke & Pb & Zn & OC & RCM & PM & \%RCM \\
\hline TAL & 23.9 & 7.63 & 0.00 & 0.64 & 1.33 & 0.00 & 34.9 & 35.8 & 97.2 \\
\hline CGL & 23.8 & 6.80 & 0.00 & MDL & 2.09 & 0.00 & 33.8 & 31.1 & 109 \\
\hline CML & 30.8 & 7.02 & 0.00 & 0.91 & 0.97 & 70.81 & 111 & 151.4 & 73.7 \\
\hline HPL & 39.3 & 8.07 & 0.00 & MDL & 0.26 & 0.00 & 48.7 & 60.2 & 81.0 \\
\hline CR & 16.8 & 6.95 & 0.00 & MDL & 0.26 & 0.00 & 25.6 & 26.5 & 96.8 \\
\hline MMD & 29.1 & 8.09 & 0.00 & 0.44 & 1.53 & 0.00 & 40.2 & 68.0 & 59.0 \\
\hline NDT & 32.2 & 8.17 & 0.00 & 0.62 & 0.49 & 0.00 & 42.4 & 36.5 & 116 \\
\hline AUR & 24.5 & 7.50 & 0.00 & 0.65 & 1.64 & 0.00 & 35.2 & 39.1 & 89.9 \\
\hline EL & 23.8 & 7.09 & 2.20 & 0.70 & 1.10 & 0.00 & 35.3 & 40.0 & 88.3 \\
\hline MMDX & 15.8 & 7.02 & 0.00 & MDL & 0.61 & 0.00 & 24.8 & 27.0 & 91.8 \\
\hline ES & 50.2 & 12.8 & 0.59 & MDL & 0.58 & 115 & 181 & 153 & 118 \\
\hline LR & 31.7 & 3.40 & 0.00 & MDL & 0.18 & 0.0 & 36.3 & 53.1 & 68.4 \\
\hline EW & 51.9 & 2.61 & 0.00 & 0.58 & MDL & 119 & 176 & 149 & 118 \\
\hline GAD & 53.0 & 2.13 & 0.00 & MDL & MDL & 122 & 178 & 131 & 136 \\
\hline SED1 & 16.5 & 4.08 & 0.00 & 0.44 & MDL & 0.0 & 23.4 & 43.2 & 54.1 \\
\hline SED2 & 27.2 & 2.21 & 0.00 & 0.44 & MDL & 0.0 & 32.1 & 50.8 & 63.2 \\
\hline AFD & 58.3 & 1.80 & 0.00 & MDL & MDL & 134 & 195 & 150 & 130 \\
\hline
\end{tabular}

Table. 5.

Source apportionment from $\mathrm{PM}_{2.5}$ samples $\left(\mu \mathrm{g} / \mathrm{m}^{3}\right)$ (IAP) collected from AECD campus

\begin{tabular}{|c|c|c|c|c|c|c|c|c|c|}
\hline $\begin{array}{c}\text { PM}_{2.5} \\
\text { Sample }\end{array}$ & BC & Soil & Smoke & Pb & Zn & OC & RCM & PM & $\%$ RCM \\
\hline TAL & 22.0 & 5.76 & 0.00 & MDL & 0.78 & 0.00 & 29.7 & 28.8 & 103 \\
\hline CGL & 22.7 & 6.83 & 0.00 & 0.50 & 1.94 & 0.00 & 33.3 & 29.3 & 114 \\
\hline CML & 30.4 & 7.56 & 0.00 & 0.95 & 0.60 & 69.86 & 110 & 137.7 & 79.7 \\
\hline HPL & 42.3 & 8.08 & 0.00 & MDL & 0.27 & 0.00 & 51.9 & 56.4 & 92.1 \\
\hline CR & 17.4 & 7.37 & 0.00 & MDL & 0.21 & 0.00 & 25.6 & 25.8 & 98.9 \\
\hline MMD & 26.8 & 7.19 & 0.00 & MDL & 1.31 & 0.00 & 37.0 & 57.2 & 64.7 \\
\hline NDT & 26.8 & 6.92 & 0.00 & 0.51 & 0.45 & 0.00 & 35.6 & 31.4 & 113 \\
\hline AUR & 28.6 & 6.75 & 0.00 & 0.88 & 0.35 & 0.00 & 37.1 & 36.0 & 103 \\
\hline EL & 25.8 & 6.35 & 1.32 & 0.63 & 1.00 & 0.00 & 36.0 & 32.1 & 112 \\
\hline MMDX & 17.3 & 5.51 & 0.00 & MDL & 0.57 & 0.00 & 24.2 & 26.0 & 93.2 \\
\hline ES & 46.4 & 6.90 & 1.21 & MDL & 0.49 & 107 & 163 & 113 & 144 \\
\hline LR & 37.9 & 6.51 & 0.00 & MDL & 0.65 & 0.0 & 46.1 & 45.4 & 102 \\
\hline EW & 47.0 & 3.25 & 0.00 & MDL & MDL & 108 & 161 & 116 & 139 \\
\hline GAD & 52.2 & 2.23 & 0.00 & MDL & MDL & 120 & 175 & 114 & 154 \\
\hline SED1 & 16.7 & 2.67 & 0.00 & 0.52 & MDL & 0.0 & 21.5 & 35.9 & 59.8 \\
\hline SED2 & 26.7 & 2.76 & 0.00 & 0.43 & MDL & 0.0 & 31.6 & 50.7 & 62.3 \\
\hline AFD & 59.6 & 2.22 & 0.00 & 0.57 & MDL & 137 & 200 & 137 & 146 \\
\hline
\end{tabular}


The formation of soot (OC and BC) by combustion is a complex process ${ }^{(33)}$. The fuel first undergoes pyrolysis, a process of thermal degradation and cracking of complex fuel molecules, which produces low molecular weight radicals. PAHs are formed subsequently by a series of radical reactions with soot precursors such as acetylene radicals. Further reactions with small precursor molecules result in the growth of the PAH structures until they become large enough to serve as particle nuclei. The high temperature of the flame causes most of the hydrogen to be stripped away, leaving small spherules with a high carbon - to - hydrogen ratio. These spherules form the primary component of $\mathrm{BC}$, the refractory component of soot. These spherules may coagulate, forming aggregate particles. In case of cool combustion, hydrocarbon species such as PAHs and aliphatic may adsorb on the agglomerate surfaces ${ }^{(34)}$. The reconstructed mass for the samples accounted for $55-135 \%$ of the measured mass for $\mathrm{PM}_{10}$. The least squares fit to the data gave $\mathrm{RCM}=1.18 *$ (measured mass) with $\mathrm{R}^{2}=0.85$ and shows satisfactory estimates of the $\mathrm{PM}_{10}$ components. The lowest RCM values were observed in a few laboratories for the $\mathrm{PM}_{10}$ fraction. In this study, the fraction of secondary nitrate and sulphate could not be measured. The carbonaceous material in soot particles can be divided into two categories: relatively volatile organic carbon (OC) and a nonvolatile fraction called black carbon (BC or $\mathrm{EC})$. The $\mathrm{OC}$ component of soot consists primarily of polycyclic aromatic hydrocarbons (PAH) and aliphatic hydrocarbons. The BC component is primarily graphite carbon, although the exact composition is not well known $^{(35)}$.

\section{ACKNOWLEDGEMENTS}

The authors wish to thank Ms. Sohela Akhter, The Head of the Chemistry Division, and AECD for her continued inspiration throughout the work. The authors are thankful to the staff members of the Chemistry Division for their help during the course of this work.

\section{REFERENCES}

1. M. M. Kulkarni, and R. S. Patil. An empirical model to predict ndoor $\mathrm{No}_{2}$ concentrations. Atmos. Environ. 36, 4777, 2002.

2. W. H. Organization. World Health Report; making a difference, WHO, Geneva. 1999.

3. W. H. Organization. World Health Report 2000; Health Systems:Improving Performance. WHO. Geneva. 2000.

4. K. R. Smith, J. M. Samet, I. Romieu, and N. Bruce. Indoor air pollution in developing countries and acute lower respiratory infections in children. Thorax 55, 518, 2000.

5. M. R. Pandey, P. R. Sharma, B. B. Gubhaju, G. M. Shakya, R. P. Neupane, A. Guatam, and I. B. Shrestha. Impact of a pilot acute respiratory infection (ARI) control programme in a rural community of the hill region of Nepal. Annals of Tropical Paediatrics 9, 212,1989.

6. A. Ellegard. Cooking fuel smoke and respiratory symptoms among women in low-income areas in Maputo. Environmental Health Perspective 104, 890,1996.

7. A. d. Francisco, J. Morris, A. J. Hall, J. R. M. A. Schellenberg, and B. M. Greenwood. Risk factors for mortality from acute lower respiratory tract infections in young Garbian childen. International Journal of Epidemiology 22, 1174,1993.

8. B. A. Begum, and S. K. Biswas. Comparison of PM collection efficiency of Gent and Airmatrics MiniVol Portable Air Sampler. Nuclear Science and Application I14, 79, 2005. 
9. B. A. Begum, S. Akhter, L. Sarker, and B. Swapan K. Gravimetric analysis of air filters and quality assurance in weighing. Nuclear Science and Application Submitted, 2006.

10. S. K. Biswas, S. A. Tarafdar, A. Islam, M. Khaliquzzaman, H. Tervahattu, and K. Kupiainen. Impact of unleaded gasoline introduction on the concentration of lead in the air of Dhaka, Bangladesh. J. Air and Waste Management Association 53, 1355, 2003.

11. G. R. Cass, P. M. Boone, and E. S. Macias. Emission and air quality relationships for atmospheric carbon particles in Loss Angeles, Particulate carbon: Atmospheric Life Cycle, ed. G.T.Wolff and R.L. KlimischPlenum Press, New York. 1982.

12. J. A. Rau. Aerosol Science and Technology 10, 181, 1989.

13. H. Cachier, J. Ducret, M. P. Bremond, V. Youbue, J. P. Lacaux, A. Gaudichet, and J. Baudet. Biomass burning aerosols in a savanna region of the Ivory Coast in Global Biomass Burning, ed. J.S. Levine, MIT press, Cambridge, MA. 174, 1991.

14. H. Cachier, C. Liousse, P. Buat-Menard, and A. Gaudichet. J. Atmospheric Chemistry 22, 123, 1995.

15. P. Molnar, P. Gustafson, S. Johannesson, J. Boman, L. Barregard, and G. Sallsten. Domestic wood burning and PM2.5 trace elements: Personal exposure, indoor and outdoor levels. Atmos. Environ. 39, 2643, 2005.

16. G. Bernasconi, A. Tajani, and P. Kregsamer. Mannual for QXAS/AXIL. Version 3.5, IAEA, Vienna. 2000

17. B. A. Begum, and S. K. Biswas. Quality assurance test for trace element analysis in Marine Sediment using radioistope induced XRF method. Nuclear Science and Application 14, 57, 2005.

18. P. v. Espen, and F. Adams. Calibration of tube excited energy-dispersive X-ray spectrometers with thin film standards and with fundamental constants. X-Ray Spectrometry 10, 64, 1981.

19. A. H. Khan, M. Khaliquzzaman, S. A. Tarafdar, S. K. Biswas, and A. Islam. Background air pollution studies in urban and rural areas of Bangladesh using Nuclear-related analytical techniques, NAHRES-19, Vienna, Austria. 1994.

20. R. Mason. Priciples of Geochemistry, Wiley, New York. 1966.

21. B. A. Begum, B. Swapan K, and P. K.Hopke. Multielement analysis and characterization of atmospheric particulate pollution in Dhaka. Aerosol and Air Quality Research Accepted,2006.

22. W. C. Malm, J. F. Sisler, D. Huffman, R. A. Eldred, and T. A. Cahill. Spatial and seasonal trends in particle concentration and optical extinction in the United States. J. Geophysical Research 99, 1347, 1994.

23. B. M. Jenkins, L. L. Baxter, T. R. J. Miles, and T. R. Miles. Combustion properties of biomass. Fuel proc. technology 54, 17, 1998.

24. S. Jimenez, and J. Ballester. Formation and emission of submicron particles in pulverzed olive residue combustion. Aerosol Science and Technology 38, 707, 2004.

25. R. C. Weast, and M. J. Astle (1982). CRC Handbook of Chemistry and Physics, 63rd edn (Boca Raton, Florida, CRC press Inc.).

26. C. Venkataraman, and G. U. M. Rao. Emission factors of carbon monoxide and size-resolved aerosol from biofuel combustion. Environmental Science \& Technology 35, 2100, 2001.

27. J. Zhang, K. R. Smith, R. Uma, Y. Ma, V. V. N. Kishore, L. Lata, M. A. K. Khalil, R. A. Rasmussen, and S. T. Thomeloe. Carbon monoxide from cookstoves in developing countries: 1. Emission factors. Chemosphere Global Change Science 1, 353, 1999. 
28. C. Venkataraman, G. Negi, S. B. Sardar, and R. Rastogi. Size distributions of polycyclic aromatic hydrocarbons in aerosol emissions from biofuel combustion. J. Aerosol Science 33, $503,2002$.

29. C. Venkataraman, P. Joshi, V. Sethi, S. Kohil, and M. R. Ravi. Aerosol and carbon monoxide emissions from low-temperature combustion in a sawdust packed-bed stove. Aerosol Science and Technology 38, 50, 2004.

30. R. Farmer, R. Edelmann, and E. Wong. Modeling soot emissions in combustion systems. In particulate formation during combustion, edited by D. Siegla and G. Smith. General motors research laboratories, Premium Press, New York, pp. 299-317. 1981.

31. B. A. Begum, S. K. Paul, M. D. Hossain, S. K. Biswas, and P. K. Hopke. Indoor air pollution from particulate matter emissions in different households in rural areas of Bangladesh. Building and Environment in press, 2008.

32. G. B. Wiersma, D. A. Bruns, K. Finley, L. McAnulty, C. Whitworth, and C. Boelcke. Chemosphere 24, 155, 1992.

33. H. Bockhorn.(ed). Soot formation in combustion: Mechanisms and models of soot formation. Springer series in chemical physics, Vol. 59, Springer-Verlag, Berlin. 1994.

34. I. Glassman (1996). Combustion, 3rd ed. Academic Press, San Diego, CA).

35. J. C. Slowik, K. Stainken, P. Davidovits, L. R. Williams, J. T. Jayne, C. E. Kolb, D. R. Worsnop, Y.Rudich, P. F. DeCarlo, and J. L. Jimenez. Particle morphology and density characterization by combined mobility and aerodynamic diameter measurements. Part 2 : Application to combustion-generated soot aerosols as a function of fuel equivalence ratio. Aerosol Science and Technology 38, 1206, 2004. 